\title{
Controlled Cataloging: An Experiment at Yale
}

$\mathrm{H}^{\circ}$

ow MUCH of a cataloger's time is spent surveying and sorting the material that comes to his desk? If he has to handle his own arrears, how much more time must he spend arranging them so that specific items may be found if called for? Suppose he might spend all of this time on actual cataloging, would not his production of finished work be materially increased? Could the deferred work of the entire department be organized in such a way that specific items might be found if called for and yet not be the responsibility of the individual catalogers themselves? What would be the psychological effect on catalogers if they were not surrounded by masses of undigested arrears?

Questions such as these have been disturbing us at Yale for some time and this year we decided to try an experiment of controlling the flow of material to the catalogers so that they need spend no time deciding what could be deferred; everything that came to their desks was to be cataloged promptly, and presumably there would be time left over to dig into previously deferred material. In fact, one of the incentives for the inauguration of this program was the hope of clearing up much of the old arrears that had long been accumulating around our desks and in the portion of stacks used for storage. Much of this material had been dug up from obscure recesses in the old library when we moved in 1930; much was work begun and left unfinished by resigning catalogers, and in- herited by the present staff; a great deal of it was what we call snags, unimportant in themselves but requiring patient study and hours of time for apparently small ends. All catalog departments of large libraries doubtless accumulate such problems; the pressure of incoming material forces attention on that which can be moved easily and quickly; special collections arrive unheralded and must be dealt with promptly; problems are put aside to be taken up when one has more time-and one never has. Eventually the department becomes choked with masses of material; more and more time is spent hunting through it for wanted items, less and less in cataloging; the morale of the staff suffers, and it is up to the administrator to do something about it.

Another incentive for this experiment was the possibility it offered of organizing, according to subject matter, the cataloging of non-rush material in larger lots than would be possible if it were handled volume by volume as acquired. Haskins' recent article $^{1}$ stressed this point in Harvard's plan for handling old gift material and gave impetus to our own vague ideas on the same subject.

\section{Factors Affecting Plan}

Before describing the plan inaugurated this past year as an experiment in the handling of deferred material, it will be necessary to explain a few points concerning the

1 Haskins, Susan M. "Something New in Cataloging." College and Research Libraries 6:291, September 1945. 
organization of our library, since any such plan must fit into the general scheme of work and must make use of existing routines. The primary feature of the catalog department is its organization on subject lines, so that a single group of catalogers (number depending on size of class) is responsible for classification, subject assignment, and descriptive cataloging of all books and pamphlets within its field. Serials, cataloged in the serial department, are also sent to these subject groups for classification and subject assignment, as well as rare books and books in unusual foreign languages, which are cataloged by specially qualified assistants. Documents are not set up as a group apart from the regular classes, but are treated as monographs, serials, or pamphlets, and are integrated in our classification along with other material on the same topics.

Another feature of our library organization closely affecting the work of the cata$\log$ department is the method of accessioning. Yale has no system of numbering and listing accessions in order of receipt. The accessions file is an alphabetical card file like the catalog, except that the information on the cards relates to source, cost, date of receipt, etc. All books received by purchase or exchange are accessioned but most gifts are not; hence, there is no way of locating items in the library acquired by gift until they are cataloged. Books received as gifts are searched in the catalog by the accessions department, duplicates being rejected and the rest forwarded to the catalog department. Several years ago an arrangement was made between the two departments whereby the checking assistant of the accessions department inserts a slip of paper in each book, giving the full author heading and noting the call number of any other edition in the library. The supplying of this information saves the catalogers a great deal of time and is a vital factor in the operation of our program regarding deferred material.

The sorting of books into classes for distribution to the catalogers is done daily by the head cataloger in the accessions department before the books are plated and labeled with the class letters. Thereafter the books are shelved on a large truck, wheeled to the depository catalog, and checked for printed cards by junior catalogers before being distributed to the class groups for cataloging. Any printed cards available are extracted from the depository and inserted in the books for the use of the catalogers.

Another factor affecting our plan was the existence of collections of uncataloged reserves in various parts of the library stacks, their nature and whereabouts known to few of the present staff. They stem from our early days when it was the policy to shelve material as it was received in the stacks in its proper subject place to await cataloging. Space in the catalog department in the old library was so limited that it was customary, when handling large groups of material, to send the catalogers into the stacks to do their work, to be followed by the labelers and markers, leaving the collection all properly cataloged, labeled, marked, and shelved in its correct place. Over the years we have cleared up the bulk of such uncataloged deposits, but by no means all of them.

\section{Outline of Plan}

The first decision governing our treatment of "defers" was to set them up in the large classes in which they would eventually be classified so that they might be easily accessible any time that the specific group was ready to catalog them, without the necessity of selection from a comprehensive alphabetical file of all classes.

The second decision was to arrange the books numerically under each class rather 
than alphabetically, numbering them consecutively as they were added to the file. Besides the obvious advantages of saving both the time of alphabeting each consignment and the space for an unknown number of volumes, this method had the added superiority of enabling us at any time to tell how many deferred books there were in any given class just by looking at the last number assigned and to redeploy the cataloging assistance accordingly when we were ready to undertake the cataloging of any specific class.

The third decision was to list the books by author in both public and official catalogs-in the public catalog so that specific titles could be located by readers; in the official catalog so that duplicates could be discovered by the accessions department in the checking of gifts. We also decided to bring down from the stacks the remaining uncataloged groups mentioned above, as we found time, to set them up in our single file of arrears, and to list them, too, in the cata$\log$. This decision nullified the use of the statistics of this year's defers as synonymous with this year's accessions. However, once having achieved our objective of an author card in the catalog for every book not in present process of being cataloged or revised, we can begin to count defers as current accessions and obtain some better idea of how much material is acquired annually in each class-knowledge which will be useful in the general allocation of number of catalogers to various subject groups.

\section{Inception of Plan}

The "defer" plan was conceived two years ago and its general policies approved by the administration and department heads. This is not to say that this approval was easily won. Although all were aware that there were hundreds of uncataloged books in the library, somehow it was felt that this should not be publicly acknowledged; like a skeleton in the closet, it was better kept out of sight. It was difficult to convince other department heads that the reader would be better served by this listing; that the reference assistants would be spared guessing which class might conceivably be hiding some wanted item, consulting with the cataloger, hunting through uncataloged arrears. It was difficult to convince them of the temporary nature of this listing; it seemed to them that the catalog department was proposing this as a substitute for cataloging rather than as an intermediate step between acquisition and cataloging and that once the books were sent to the defer file they would be abandoned and forgotten. We recognized this as a real danger in the program, and took steps which are explained later, to meet it.

Having won consent to the program, we were unable to implement it at that time (February 1944) because we were still suffering wartime shortages of staff and had not the necessary assistance, although we did make a beginning by sending some old gift material, without listing it in the cata$\log$, to the storage room in the basement which now houses the entire file. When the war ended we knew it would not be long before the opening of the European book markets would flood us with books held by our dealers for the past six years. It was, therefore, imperative to start the program of deferments without further delay; to allocate everything (except new imprints and books especially requested to this file, whether acquired by gift, purchase, or exchange, so that the catalogers would have as much time as possible to clear the department of old arrears before we should be swamped with more important material.

We began the actual listing last September (1945) and, besides taking care of current defers, spent the first three months 
catching up with the previously deferred books and also taking over some of the books in the catalogers' old files of arrears, so that they might spend their time on more important items and titles too difficult to be listed by the comparatively inexperienced listing staff.

\section{Selection of Defers}

The selection of titles to be currently deferred is made by the head cataloger during her daily assignment of class letters to incoming material, often with the advice of the head of the accessions department. The criterion for selection this year was simply to defer everything that could possibly be deferred, but often the decision had to be made on grounds that had nothing to do with the relative unimportance of the book. The listing staff consisted of one experienced and unusually responsible clerical worker with some foreign language background, who was in charge of the program, and part-time help from two other clerical workers, one with and one without training in foreign languages. Occasionally for large groups of foreign books we utilized specially qualified student assistants. None of the listers was experienced in cataloging, and it was therefore necessary to reject from the deferred file material that presented unusual difficulties of entry or title transcription, as well as books in Latin, Greek, Russian, and Hebrew, and books requiring more than one entry, since we did not propose to complicate the listing by making references from pseudonyms or title cards for anonyms. It was also necessary to pay some attention to the donor's name to be sure he would not be offended if his gift did not receive prompt and complete cataloging and classification. Because these various elements conditioned the selection, it was made clear to the catalogers that, no matter what the relative importance of the books seemed to be, all sent to them were to be cataloged promptly.

Pamphlets were omitted from the program, although in two classes (education and sociology) we carried on a similar policy of listing some old pamphlet files in the catalogs. These files are under the supervision of the catalogers in charge of the classes concerned and are separate from the main deferred file. The slips made for these have the letter "p" preceding the number assigned to each pamphlet, to distinguish this file from the book file.

\section{Techniques of the Plan}

Books selected to be deferred have the word "defer" written on the slip indicating the class letter, which the head cataloger inserts in each book as she classifies it for distribution. This warns the plating staff to segregate these books, after labeling, and to sort them by class on shelves in that department. The listing staff is responsible for taking the books from these shelves by truck loads, wheeling them to the typing room, making the brief record for the cata$\log$, and, finally, after revision of the work, shelving the books in the basement storage room. For quick filing and location of the books a stiff paper tag about one inch wide is inserted in each book, bearing the penciled class notation consisting of the class letter, followed on second line by the word "uncat," and on third line by number of $\mathrm{K}$ the book in the class (e.g., uncat.), the 45

same notation being typed as a call number on the slip for the catalog. In addition to the slips for the public and official catalogs, another carbon is made to serve as the cataloger's work slip when he is ready to catalog his group. For these temporary records we use strips with six card size divisions, perforated for easy detachment, 
enabling the typist to list six books without having to remove and insert slips for each in the typewriter. The paper used in these strips is slightly heavier than ordinary pad paper and can be filed more easily in a card file.

The slips contain full author headings, brief titles, edition information, place, and date of publication. Information given on the checking slip inserted in each book is copied on the cataloger's work slip by the reviser of the listing; the fact that there are other editions in the library is significant in the organization of the cataloging, since such items present few problems, a subject approach being already available in the cata$\log$, and they furnish a type of material that can be handled by less experienced assistants.

As explained above, the complete author heading for each book received as a gift and information as to other editions in the library appears on a slip of paper inserted in the book by the accessions department. This information does not appear in books received by purchase or exchange, because such titles are checked in advance of ordering, and no information is sent along in the books. Since the defer program is intended primarily to care for gift material, generally no time need be spent by the listing staff in the checking of the catalog. However, in January the delayed shipments from Europe began pouring in so fast that we had to add to our defer file a great deal of material coming by purchase or exchange, which required some checking for headings and other edition information. Many thousands of dissertations arriving on exchange from France, Switzerland, Belgium, the Netherlands, and the Scandinavian countries, serial analytics from foreign societies and academies for which cards will eventually be printed by Library of Congress or cooperating libraries, books distributed to us by the cooperative acquisitions program of foreign materials; as well as individual orders through our own dealers have swelled our accessions during the past six months to unprecedented figures for this period of time. Most of this material has been bedded down in the defer file, because ( $I$ ) we did not want to interfere with our program of clearing old arrears, (2) we expect printed cards will be available for much of it in a few months, and (3), by using the third slip to organize the material in each class by topics, or,-in the case of literature, by author, single groups may be handled more economically and rapidly. Often large gifts on a limited subject are received and cannot be checked by the accessions department as a unit, because of the pressure of other work. Books in these gifts are dispatched intermittently to the catalog department, interspersed with other subject material. This no longer proves annoying because we now simply list them as they come along, and, when the last book in such a gift has been passed through the accessions department, we can go back through our defer slips and pick out all the books on a given topic for cataloging as a unit.

\section{Methods of Cataloging}

In organizing the cataloging of groups of defers, we were able to effect some economies over our regular routines in the checking and ordering of printed cards, eliminating the refiling of depository cards by not withdrawing them. Details of this procedure would be of interest only to libraries whose routines are organized along lines similar to Yale's, and are therefore omitted here. The principal objective in the handling of the defers is to have the lapse of time between the disruption of the book file and the filing of permanent cards for the finished work as brief as possible, so that 
no difficulty need arise in the location of any item called for by a reader. Books are not sent for by the cataloger until as much as possible of the preliminary work is done and the sets of printed cards are in hand, insofar as they may be obtained. Thereafter the group is handled promptly and moves along as a unit to the reviser, thence to the marker and the shelves. Cards sent to the typing staff are earmarked for rush handling, proofreading is dispatched promptly, and cards distributed to the files in as short a time as possible. From the inception of the plan, we agreed to catalog on demand any book called for by a reader and worked out a routine with the circulation department for the handling of such requests.

To offset the danger of failing to keep the defers moving along through the cataloging process we have dated all the slips as they are distributed to the files. The consecutive numbering enables us to set a time limit for clearing up the books deferred over a definite period. All tags for books cleared are returned to the listing staff and will eventually be used again; this will enable us to catch any odd volumes left behind in the clearing-up process. Our intention now is to number continuously for two years in each class, with the expectation that in that time sufficient progress will have been made in the cataloging program to allow for the re-use of the numbers assigned the first year. If the cataloging program does not keep pace with the listing program we shall run into statistical complications and also into shortage of space for the defer file, both of which should prove compelling in keeping up with the program as planned.

\section{Results}

When we inaugurated this program it was with the definite idea of clearing the bulk of the file through a concerted drive by each class group the following spring. Many factors conspired to make this goal unattainable in its entirety: the listing of material long in the library, the opening of the European book markets, and the acquisition of two large special subject collections which are not yet fully listed. Our conception of the plan has been altered by circumstances, but some classes have managed to catalog completely all of their listed defers; one or two have not made even a beginning; the majority have cleared part of their assignment. The largest single group cataloged was in the class of English and American literature which had the greatest number of listed defers, 600 at the time the cataloging began, 1229 by the end of May.

In all, we listed 5895 defers between late September 1945 and May 31, 1946, when our annual statistics were reported, averaging twelve titles per hour. In the two months we spent cataloging these defers we cataloged about one thousand, including forty requested by readers. We shall continue the program but shall expect the las between listing and cataloging to grow shorter, as we clear the last remaining dregs from our department shelves. We do not know how successful this experiment has seemed to other departments, but in the catalog department we are convinced that it has served a very useful purpose by enabling us to clear up nearly all back work in every class, to put new hope into us as we have seen old files disappearing and to plan our work more systematically. We now have for the first time a statistical record of uncataloged material in every class, evidence that some classes are overstaffed and some greatly understaffed according to their accessions; it remains for us to remedy these inequities and effectively coordinate accessions and cataloging. 